International Journal of Current Advanced Research

ISSN: O: 2319-6475, ISSN: P: 2319 - 6505, Impact Factor: SJIF: 5.995

Available Online at www.journalijcar.org

Volume 6; Issue 4; April 2017; Page No. 3376-3378

DOI: http://dx.doi.org/10.24327/ijcar.2017.3378.0278

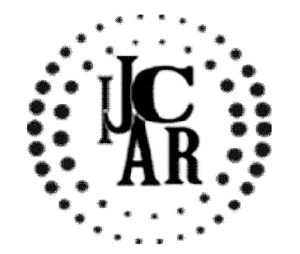

Research Article

\title{
EMPHYSEMATOUS PYELONEPHRITIS-ROLE OF CONSERVATIVE MANAGEMENT AND DRAINAGE PROCEDURES-INSTITUTIONAL EXPERIENCE
}

\section{Senthil Kumar Thiagarajan*., Arjun Pon Avudaiappan and Senthil Dhanapal}

Department of Urology, SRM Medical College Hospital and research Centre, Kattankulathur, Tamilnadu.

\begin{tabular}{l}
\hline A R T I C L E I N F O \\
\hline Article History: \\
Received $20^{\text {th }}$ January, 2017 \\
Received in revised form $19^{\text {th }}$ February, 2017 \\
Accepted $22^{\text {nd }}$ March, 2017 \\
Published online $28^{\text {th }}$ April, 2017 \\
\end{tabular}

Key words:

Emphysematous Pyelonephritis, Percutaneous Drainage, Urosepsis, Nephrectomy

\begin{abstract}
A B S T R A C T
Introduction: Emphysematous pyelonephritis is a fulminant infection of the renal parenchyma by gas forming organisms that lead to collection of gas in the renal parenchyma and collecting system. Uncontrolled diabetic status, obstruction predispose for infection. Most common organism is E.coli. Failure to diagnose at an earlier stage can lead to mortality. Early diagnosis and efficient conservative management can reduce morbidity and mortality. Materials and methods: Retrospective analysis of cases admitted and managed as emphysematous pyelonephritis over a period of 2 years. Patients admitted with renal colic, features of sepsis and radiological evidence of gas in renal parenchyma or PCS were analyzed. Out of 135 cases admitted for urosepsis 15 cases had evidence of gas in PCS. All the cases were investigated with urinalysis, urine culture, blood biochemistry, plain X-ray, and CT scan. Treatment started with Cefperazone + sulbactum and supportive measures. If there is no response within $24-36$ hours antimicrobial changed to meropenum. Operative management was reserved for patients who do not respond to conservative treatment. Results: Of the 15 cases 9 were male and 6 female in the age group 45 to 65 years. Left renal system involved in 7 cases, right in 7 cases and 1 case had gas in both kidneys. All the patients were diabetics with poor glycemic control. Presentation was fever, loin pain and azotemia. Urine culture showed E.coli in all the cases. As per CT based classification 5 cases (33.3\%) were class 1,2 cases (13.3\%) were class 2,7 cases $(46.6 \%)$ were class 3 and 1 case $(6.6 \%)$ was class 4 . In our series mortality was $0 \%$ (no cases), $46.6 \%$ ( 7 cases) needed no surgical intervention, 20\% (3 cases) underwent DJ stenting alone, $13.3 \%$ ( 2 cases) had DJ stenting with percutaneous drainage, $13.3 \%$ (2 cases) underwent partial nephrectomy and $6.6 \%$ (1 case) was managed with nephrectomy. Stent was removed after 4 weeks and PCD 8 to 10 days. Conclusion: EPN is a life threatening infection of the kidneys was treated by primary nephrectomy earlier. Availability of newer antimicrobials effective against most of the gas forming organisms and earlier diagnosis changed the scenario from radical to conservative management saving more renal units.
\end{abstract}

Copyright $(2017$ Senthil Kumar Thiagarajan et al. This is an open access article distributed under the Creative Commons Attribution License, which permits unrestricted use, distribution, and reproduction in any medium, provided the original work is properly cited.

\section{INTRODUCTION}

Emphysematous pyelonephritis is a fulminant infection of the renal parenchyma by gas forming organisms that lead to collection of gas in the renal parenchyma and collecting system. Uncontrolled diabetic status and obstruction predispose to infection but EPN can affect non diabetics and can occur without obstruction. Commonest organism isolated is Escherichia coli. Early diagnosis with efficient conservative management in the form of antibiotic and minimally invasive procedures can reduce morbidity and mortality leading on to more renal units being salvaged. Failure to diagnose at an earlier stage can lead to loss of functional renal units and even mortality.

*Corresponding author: Senthil Kumar Thiagarajan Department of Urology, SRM Medical College Hospital and research Centre, Kattankulathur, Tamilnadu.

\section{MATERIALS AND METHODS}

Retrospective analysis of cases admitted and managed as emphysematous pyelonephritis over a period of 2 years from March, 2014 to February, 2016. Patients admitted with renal colic, features of sepsis and radiological evidence of gas in renal parenchyma or PCS were included. Out of 135 cases admitted for urosepsis 15 cases $(11.1 \%)$ had evidence of gas in PCS. Urinalysis, urine culture, blood biochemistry, plain xray, and CT scan reports were analyzed. Initial management was with intravenous antibiotic $1 \mathrm{gm}$ of ceftriaxone sodium with sulbactum twice a day and other supportive measure. Antimicrobial agents were changed to meropenum with piperacillin if there is no clinical response within 24 to 36 hours. Surgical management was reserved for patients who do not respond to conservative treatment. Minimally invasive procedures- DJ stenting and percutaneous drainage were done 
in selected cases. Nephrectomy was considered as last choice keeping nephron saving as main aim of management.

\section{RESULTS}

Age distribution was 45 years to 68 years with 4 cases less than 50 years, 6 cases between 51 to 60 years and 5 cases between 61 to 70 years. Male: female distribution was 9:6. Out of 15 cases, 7 cases had left sided lesion, 7 cases were right sided and 1 case was bilateral involvement.

Table 1 Clinical features and hemogram

\begin{tabular}{|c|c|c|c|}
\hline Clinical features & Fever & \multicolumn{2}{|c|}{ All cases $(100 \%)$} \\
\hline \multirow{6}{*}{$\begin{array}{l}\text { Complete } \\
\text { hemogram }\end{array}$} & & $<10$ gms $\%$ & $2(13.3 \%)$ \\
\hline & $\mathrm{Hb} \%$ & $10-12 \mathrm{gms}^{2} \%$ & $5(33.3 \%)$ \\
\hline & & $>12$ gms $\%$ & $8(53.3 \%)$ \\
\hline & & $<40000$ & $4(26.6 \%)$ \\
\hline & Platelet count & $40000-100000$ & $6(40 \%)$ \\
\hline & & $>100000$ & $5(33.3 \%)$ \\
\hline
\end{tabular}

Clinical symptoms of fever and loin pain were present in all cases. On investigation, hemoglobin was normal $>12 \mathrm{gms} \%$. in 8 cases, $<10 \mathrm{Gms} \%$. in 1 case and rest 6 cases between 10 to $12 \mathrm{Gms} \%$. Platelet count was $<40000$ in 4 cases, normal in 5 cases and 6 cases had 40000 to 100000 .

Table 2 Blood biochemistry and urine culture

\begin{tabular}{cccc}
\hline & \multirow{2}{*}{ Blood urea } & $\mathbf{4 0 - 6 0 \mathbf { ~ m g }}$ & $\mathbf{2 ( 1 3 . 3 \% )}$ \\
\cline { 3 - 4 } Blood & & $-100 \mathrm{mg}$ & $5(33.3 \%)$ \\
biochemistry & & $>100 \mathrm{mg}$ & $8(53.3 \%)$ \\
& & $<2 \mathrm{mg}$ & $3(20 \%)$ \\
& Serum creatinine & $2-5 \mathrm{mg}$ & $6(40 \%)$ \\
Urine culture & Eschericia coli & $>5 \mathrm{mg}$ & $6(40 \%)$ \\
\hline
\end{tabular}

Table 3 CT scan and CT basedclassification (Huang et al 2000)(1)

\begin{tabular}{cccc}
\hline Class & Characteristics & No. of cases & $\mathbf{\%}$ \\
\hline Class 1 & $\begin{array}{c}\text { Gas confined to PCS } \\
\text { Gas confined to renal } \\
\text { parenchyma alone }\end{array}$ & 5 & $33.3 \%$ \\
Class 2 & $\begin{array}{c}\text { Perinephric extension of gas or } \\
\text { abscess }\end{array}$ & 4 & $13.3 \%$ \\
Class 3A & $\begin{array}{c}\text { Extension of gas beyond Gerotas } \\
\text { fascia }\end{array}$ & 3 & $26 \%$ \\
Class 3B & $\begin{array}{c}\text { Class 4 } \\
\text { Bilateral EPN or EPN in solitary } \\
\text { kidney }\end{array}$ & 1 & $6.6 \%$ \\
\hline
\end{tabular}

Table 4 Management

\begin{tabular}{ccc}
\hline Management & No. of cases & $\mathbf{\%}$ \\
\hline No surgical intervention & 7 cases & $46.6 \%$ \\
DJ stenting & 3 cases & $20 \%$ \\
DJ stenting with PCD & 2 cases & $13.3 \%$ \\
Partial nephrectomy & 2 cases & $13.3 \%$ \\
Nephrectomy & 1 case & $6.6 \%$ \\
Mortality & Nil & $0 \%$ \\
Total & 15 cases & $100 \%$ \\
\hline
\end{tabular}

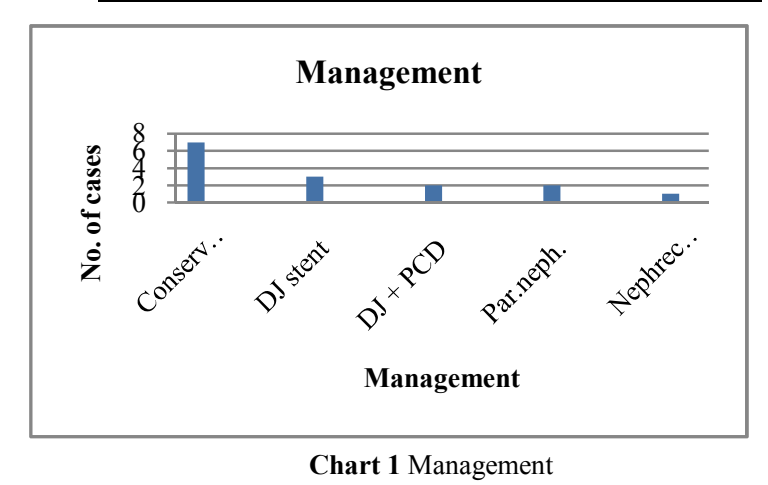

$100 \mathrm{mg}$ in 5 cases with serum creatinine ranging from $<2 \mathrm{mg}$ in 3 cases, 2 to $5 \mathrm{mg}$ in 6 cases and $>5 \mathrm{mg}$ in 6 cases.

Urine culture showed growth of E.coli in all cases and all cases were diabetics with poor glycemic control. CT based classification showed 5 cases in class 1,2 cases in class 2, 4 cases in class $3 \mathrm{~A}, 3$ cases in class $3 \mathrm{~B}$ and 1 case in class 4.7 cases were managed conservatively, DJ stenting in 3 cases, DJ with percutaneous drainage in 2 cases, partial nephrectomy in 2 cases and nephrectomy in 1 case. There was no mortality in our series.

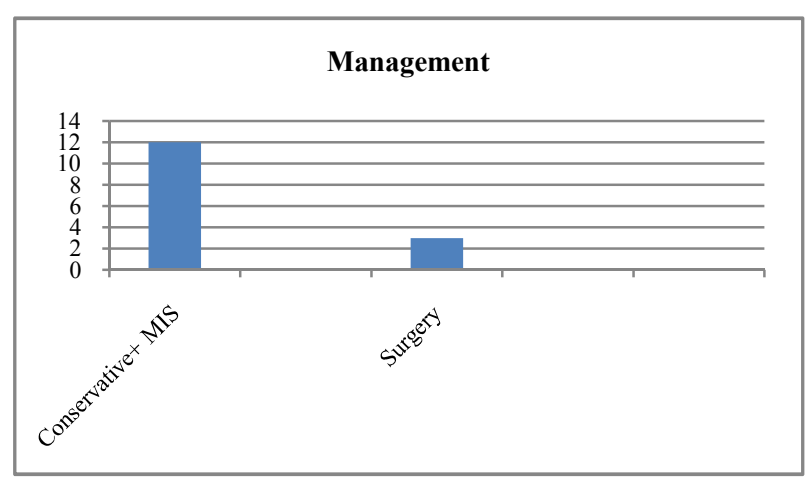

Chart 2 Management of Emphysematous pyelonephritis

\section{DISCUSSION}

Emphysematous pyelonephritis (EPN) is a rare but potentially life threatening necrotizing renal parenchymal infection characterized by the production of intraparenchymal gas. Till 1980 the standard treatment for EPN was nephrectomy because conservative treatment leads to a mortality of 60 $80 \%$. EPN is common in diabetic patients and can occur in non diabetics also. Commonest organisms isolated are Escherichia coli and Klebsiella pneumoniae. Thrombocytopenia, shock, altered sensorium and renal functional compromiseare considered as bad prognostic factors. In the last two decades, CT scan made earlier diagnosis possible and helps in assessing the extent or spread of the disease (2). Availability of broad spectrum antimicrobials helped in efficient control of infection ${ }^{(3)}$ Minimally invasive procedures enabled drainage of pus and necrotic materials feasible and reduced the morbidity and mortality of major surgical interventions with good prognosis $^{(4)}$. Although nephrectomy may be the quickest way of treating the infection source, renal function is compromised in many patients; therefore, a strategy to save nephrons may be very desirable. Control of diabetes and maintenance of adequate fluid balance should be achieved quickly. Initial antibiotic therapy consists of intravenous antimicrobials and is administered until the culture and sensitivity results are available. Patients should be treated with aggressive medical management and prompt surgical intervention. Huang and Tseng (2000) reported 66\% success rate with percutaneous drainage and antibiotics in patients with EPN, while Aswathaman et al (2008) found an 80\% success rate ${ }^{[5]}$. In our series of 15 cases $73.3 \%$ (11 cases) were above 50 years with a male: female ratio of $3: 2$ and 2 cases $(13.3 \%)$ had bilateral involvement with rest distributed equally between right and left. Loin pain and fever were the presenting complaint in all cases. Hemoglobin decreased $<10$ gm $\%$ in 2 cases $(13.3 \%)$, and was normal in 8 cases $(53.3 \%)$ and 10 to $12 \mathrm{gm}$ in 5 cases $(33.3 \%)$. Thrombocytopenia with platelet count $<40000$ was seen in 4 cases $(26.6 \%)$ and was 
normal $>100000$ in 5 cases $(33.3 \%)$ with 6 cases $(40 \%)$ in the range of 40000 to 100000 . Azotemia with serum creatinine value of $>5 \mathrm{mg}$ was present in 6 cases $(40 \%),<2 \mathrm{mg}$ in 3 cases $(20 \%)$ and between 2 to $5 \mathrm{mg}$ in 6 cases (40\%). All the patients were diabetics with poor glycemic control. CT scan revealed class 1 EPN in 5 cases $(33.3 \%)$, class 2 EPN in 2 cases $(13.3 \%)$, class $3 \mathrm{~A}$ EPN in 4 cases $(26.6 \%)$, class $3 \mathrm{~B}$ EPN in 3 cases $(20 \%)$ and class 4 EPN in 1 case $(6.6 \%)$. Management wise nearly 12 cases $(80 \%)$ were managed conservatively with antibiotics and other supportive measures and minimally invasive procedures and surgical exploration was necessary only in 3 cases $(20 \%)$ and there was no mortality. 7 cases $(46.6 \%)$ were managed conservatively, DJ stenting in 3 cases $(20 \%)$, DJ with percutaneous drainage in 2 cases $(13.3 \%)$, partial nephrectomy in 2 cases $(13.3 \%)$ and nephrectomy in 1 case $(6.6 \%)$. Higher the class chances of surgical management is high. Surgical exploration and salvage with partial nephrectomy and nephrectomy was necessary in 2 out of 3 cases $(66.6 \%)$ in class $3 \mathrm{~B}$ and $100 \%$ in class 4 case. Risk factors such as thrombocytopenia, acute renal insufficiency, altered mental status, and shock at presentation influenced decision making regarding early or deferred surgical intervention. Cases presented with altered sensorium, thrombocytopenia were the ones where surgical intervention was done.

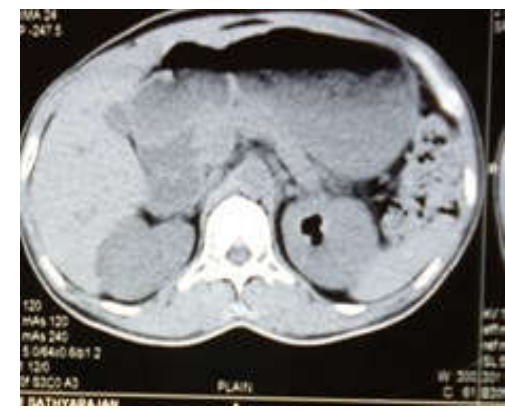

Fig 1 Class I

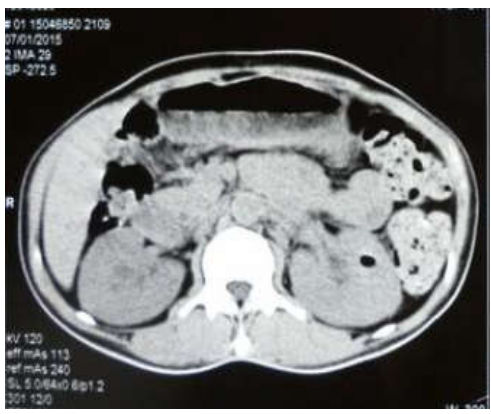

Fig 2 Class II

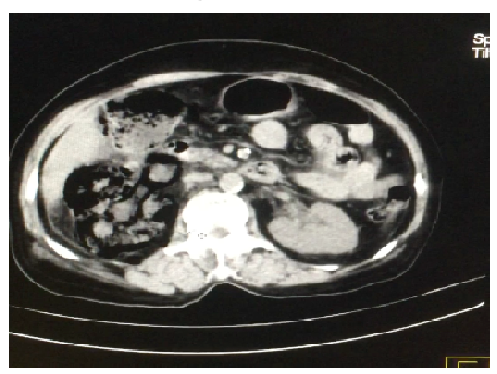

Fig 3 Class III B

\section{CONCLUSION}

EPN is a life threatening infection of the kidneys that was treated by primary nephrectomy earlier. Availability of newer antimicrobials effective against most of the gas forming organisms and earlier diagnosis with $\mathrm{CT}$ scan and interventions like double $\mathrm{J}$ stenting and percutaneous drainage has changed the scenario from radical to conservative management saving more renal units. These procedures could be done under local anesthesia without exposing the high risk patients to general anesthesia. Our series highlights the approach, reserving nephrectomy for patients in whom conservative treatment fails to elicit a response.

\section{References}

1. Huang JJ, Tseng CC. Emphysematous pyelonephritis: clinicoradiological classification, management, prognosis, and pathogenesis. Arch Intern Med. 2000 Mar 27. 160(6):797-805.

2. Uruc F, Yuksel OH, Sahin A, Urkmez A, Yildirim C, Verit A. Emphysematous pyelonephritis: Our experience in managing these cases. Can Urol Assoc J. 2015 Jul-Aug. 9 (7-8):E480-3.

3. Aboumarzouk OM, Hughes O, Narahari K, Coulthard $\mathrm{R}$, Kynaston $\mathrm{H}$, Chlosta $\mathrm{P}$, et al. Emphysematous pyelonephritis: Time for a management plan with an evidence-based approach. Arab J Urol. 2014 Jun. 12 (2):106-15.

4. Nana GR, Brodie A, Akhter W, Karim O, Motiwala H. Nephroureterectomy for emphysematous pyelonephritis: An aggressive approach is sometimes necessary. A case report and literature review. Int $J$ Surg Case Rep. 2015. 10:179-82.

5. Aswathaman K, Gopalakrishnan G, Gnanaraj L, Chacko NK, Kekre NS, Devasia A. Emphysematous pyelonephritis: outcome of conservative management. Urology. 2008 Jun. 71(6):1007-9. 